\title{
Structure and Material Usages Concerning Sustainability in Architectural Design Studio
}

\author{
Ebru Alakavuk ${ }^{1 *}$ \\ ${ }^{1}$ Yasar University, Üniversite Street No:37-39 Ağaçlıyol Bornova, İzmir, Turkey
}

\begin{abstract}
Sustainability is a term that there is no exact definition that is accepted for everyone. But the main acceptance is that goods and services that use resources that can be replaced. As it is clear that climate change is one of the big problems of the world nowadays, sustainability becomes an important subject of the world. Day by day people become more conscious about sustainability and try to live environmentally friendly. In such a condition sustainability in architectural design becomes more important. In this paper applying sustainability concepts on architectural design is discussed. In the third year architectural design studio students are supposed to design a sustainable project that is respectable to the environment and also using renewable energy sources. The aim of this paper is to put forward integration of sustainability with respect to material usage in architectural design. The projects of third year studio students are taken as a case study and integration of sustainable structures and materials to architectural design is discussed.
\end{abstract}

\section{Introduction}

Climate change is one of the global problems that world faces in nowadays. As the climate changes, sea level has risen, typhoons may cause more damage, average rainfall has increased, hot temperatures can be dangeruos for human health and also changing weather conditions can effect the ranges of plants and animals. For reducing the impacts of climate change people has to take precautions. One of the precaution that can be done is being sustainable. As buildings consume most of the energy, sustainability of the buildings is important. Architects must think about energy consumption and sustainability for living in healthy environment.

There is much talk of 'sustainable development' and little comprehension of its meaning. It is very evident that those involved in the so-called 'green' movement are characterized by their passion, [1]. Estimates of likely future adaptations are an essential ingredient in impact and vulnerability assessments. The extent to which ecosystems, food supplies, and sustainable development are vulnerable or "in danger" depends both on exposure to changes in climate and on the ability of the impacted system to adapt. In addition, adaptation is an important policy response option, along with mitigation. There is a need for the development and assessment of planned adaptation initiatives to help manage the risks of climate change [2].

Adaptation also is considered an important response option or $\mathrm{s} \mathrm{t} r$ a t e g y, along with mitigation $[3,4,5,6]$. Even with reductions in greenhouse gas (GHG) emissions, global 
temperatures are expected to increase, other changes in climate-including extremes - are likely, and sea level will continue to rise [7, 8, 9]. Hence, development of planned adaptation strategies to deal with these risks is regarded as a necessary complement to mitigation actions $[10,11,12,13]$. Article 4.1 of the UNFCCC commits parties to formulating, cooperating on, and implementing "measures to facilitate adequate adaptation to climate change." The Kyoto Protocol (Article 10) also commits parties to promote and facilitate adaptation and deploy adaptation technologies to address climate change.

One of the ways of adaptation to the climate change is being sustainable. As most of the energy consumption is done by the buildings, being sustainable and using sustainable principles in buildings is getting important day by day.

\section{Structure and material usages concerning sustainability in architectural design studio}

Mostly every architecture faculty has theoretical courses including sustainability. But integrating sustainability principles in to architectural design is difficult. In this paper adaptation of the sustainability principles to architectural design and how to make the building sustainable by using different materials and structures is discussed. To emphasize and to achieve a consciousness of the sustainability, third year architecture design studio focused on it. Third year architecture design studio and it's outcomes is taken as a case study of this paper.

It was a challenge for students to design with sustainable principles. As sustainability has many ways to apply, students tried to adapt different principles of it into their design. They firstly tried to find new methods, systems, structures and materials for their designs. After that they searched deeply the applicability of the systems. Some of the projects have used different materials and methods for cleaning the surrounding air, collecting rain water, producing energy from sun and waves, using natural ventilation, using biomass and using wind energy. Whereas one of the project used fibre forced polyester for a temporary sustainable project. In this design besides sustainability it can take precautions for climate change. As it is known one of the results of the climate change is the rising the level of sea. This project and the interior spaces of it will not have any damage even if it goes under water. Another project work on the materials for producing energy with algae. This project designed algae producing units as façade elements in building scale and also as separation elements in landscape. The ones that are used on façade are also has the function of shading and providing privacy. As the algae in tubes get larger in volume, the colour of the water in the tubes located on facade get darker achieving the function of sun shading (fig1, fig2). Students learned how to design sustainable project by hands on doing method.
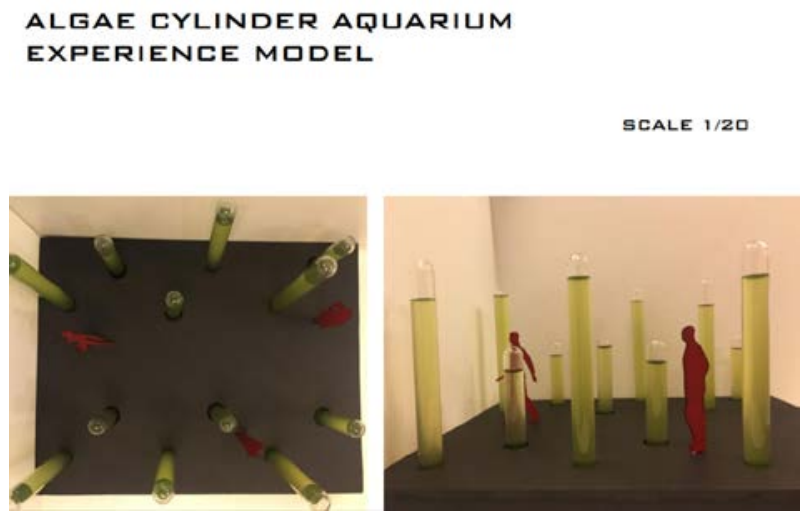

Fig 1. Experiment with algea tubes 

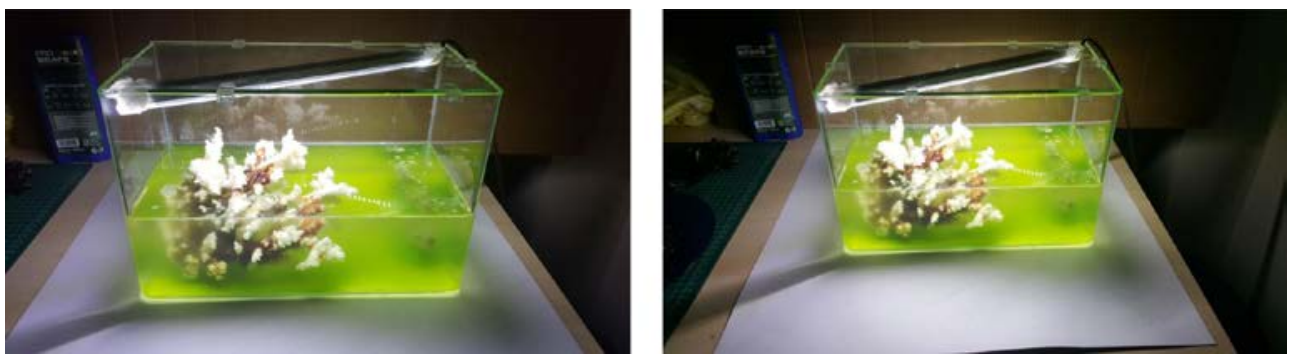

Fig 2. Experiment with algea aquarium

In design process concerning sustainability is important for living in a healthy world. Using renewable sources and energy efficiently can make big changes in our lives quality. Evaluation the importance of sustainability in architectural design is the significance of this paper. Because sustainability in designs can let the architectural design be environmentally friendly. By being sustainable, effects of the serious problems of the world which is climate change and be decreased. In this paper several methods are used. These are; literature review, evaluation of design with sustainability and observing the architectural design process.

The results of this study point out the integration of sustainability principles to architectural design. With this awareness of sustainability on design the energy consumption of buildings can be decreased. Different materials and structures concerning sustainability are put forward by this paper. And with case studies taken from the third year architectural design studio, the application methods of these systems to architectural design is introduced.

\section{References}

1. Smith, Peter F., Architecture in a Climate of Change, A guide to sustainable design Architectural Press, in Great Britain, p2, (2001).

2. B. Smit, O. Pilifosova Adaptation to Climate Change in the Context of Sustainable Development and Equity, p879

3. Fankhauser, S., The potential costs of climate change adaptation. In: Adapting to Climate Change: An International Perspective [Smith, J., N. Bhatti, G. Menzhulin, R. Benioff, M.I. Budyko, M. Campos, B. Jallow, and F. Rijsberman (eds.)]. SpringerVerlag, New York, NY, USA, pp. 80-96, (1996).

4. Smith, J.B. and S.S. Lenhart, Climate change adaptation policy options. Climate Research, 6(2), 193-201, (1996)

5. Pielke, R.A., Rethinking the role of adaptation in climate policy. Global Environmental Change, 8(2), 159-170, (1998).

6. Kane, S.M. and J.F. Shogren, Linking adaptation and mitigation in c 1 imate change policy. Climatic Change, 45(1), 75-102, (2000).

7. Raper, S.C.B., T.M.L. Wigley, and R.A. Warrick, Global sea level rise: past and future. In: Sea Level Rise and Coastal Subsidence: Causes, Consequences and Strategies [Milliman, J.D. and B.U. Haq (eds.)]. J. Kluwer Academic Publishers, Dordrecht, The Netherlands, pp. 11-45, (1996).

8. White, R. and D. Etkin, Climate change, extreme events and the Canadian insurance industry. Natural Hazards, 16, 135-163, (1997). 
9. Wigley, T.M.L., The Science of Climate Change: Global and U.S. Perspectives. Pew Center for Climate Change, Washington, DC, USA, 48 pp, (1999).

10. Burton, I., The growth of adaptation capacity: practice and policy. In: Adapting to Climate Change: An International Perspective [Smith, J., N. Bhatti, G. Menzhulin, R. Benioff, M.I. Budyko, M. Campos, B. Jallow, and F. Rijsberman (eds.)]. SpringerVerlag, New York, NY, USA, pp. 55-67, (1996).

11. Parry, M., N. Arnell, M. Hulme, R. Nicholls, and M. Livermore, Adapting to the inevitable. Nature, 395, 741-742, (1998).

12. Smit, B., D. McNabb, and J. Smithers, Agricultural adaptation to climate change. Climatic Change, 33, 7-29, (1996).

13. Parry, M., N. Arnell, M. Hulme, R. Nicholls, and M. Livermore, Adapting to the inevitable. Nature, 395, 741-742, (1998).

14. Smit, B., I. Burton, R.J.T. Klein, and R. Street, The science of adaptation: a framework for assessment. Mitigation and Adaptation Strategies for Global Change, 4, 199-213, (1999). 